\title{
Long-Term Efficacy of Botulinum A Toxin for Blepharospasm and Hemifacial Spasm
}

\author{
Harmeet S. Gill, Stephen P. Kraft
}

\begin{abstract}
Objective: To determine whether the duration of relief from symptoms in patients with essential blepharospasm (EB) or hemifacial spasm (HFS) who receive serial treatments with botulinum toxin type A (BtA) changes over the long-term. Methods: Retrospective longitudinal comparative analysis. The main outcome measure is the mean duration of relief from symptoms after an injection with BtA. Participants included 34 patients who received 30 or more serial BtA treatments for facial dyskinesia (EB or HFS). Repeated measures and linear regression analyses were used to determine trends and the mean duration of relief from symptoms was compared between early (first ten effective treatments) and late (last ten treatments) sessions in each group. Results: In the EB group (18 patients), the mean duration of relief was 13.5 weeks for the early and 11.4 weeks for the late sessions $(\mathrm{P}=0.04)$. In the HFS group (16 patients) the mean duration of relief was 12.4 weeks in both treatment periods $(\mathrm{P}=0.91)$. The duration of relief had a small negative correlation with mean late session BtA dose in the EB group $(\mathrm{P}=0.03)$ but no correlation in the HFS group $(\mathrm{P}=0.12)$. Conclusions: There was a trend towards a decreased duration of relief from symptoms in patients with EB over the long-term, but no changes for HFS. The treatment remains effective in relieving symptoms and signs for both conditions.
\end{abstract}

RÉSUMÉ: Efficacité à long terme de la toxine botulique de type A dans le traitement du blépharospasme et du spasme hémifacial. Objectif : Le but de l'étude était de déterminer si la durée de soulagement des symptômes chez les patients atteints de blépharospasme essentiel (BSE) ou de spasme hémifacial (SHF) qui ont reçu des traitements en série par la toxine botulique de type A (BtA) change à long terme. Méthodes : Il s'agit d'une étude longitudinale rétrospective. L'issue primaire était la durée moyenne de soulagement des symptômes après une injection de BtA. L'étude porte sur 34 patients qui ont reçu plus de 30 traitements en série au moyen de la BtA, pour des dyskinésies faciales (BSE ou SHF). Des mesures répétées et des analyses de régression linéaires ont été utilisées pour déterminer la tendance. La durée moyenne du soulagement des symptômes a été comparée entre les première sessions (les 10 premiers traitements efficaces) et les sessions tardives (10 derniers traitements) dans chaque groupe. Résultats : Dans le groupe BSE (18 patients), la durée moyenne de soulagement était de 13,5 semaines pour les premiers traitements et de 11,4 semaines pour les derniers $(\mathrm{p}=0,04)$. Dans le groupe SHF (16 patients), la durée moyenne de soulagement était de 12,4 semaines au cours des deux périodes de traitement $(\mathrm{p}=0,91)$. La durée du soulagement avait une faible corrélation négative avec la dose moyenne de BtA des dernières sessions dans le groupe BSE $(p=0,03)$ mais pas de corrélation dans le groupe SHF $(p=0,12)$. Conclusions : Il existait une tendance à long terme vers une durée moindre du soulagement chez les patients atteints de BSE mais pas de changement chez ceux atteints de SHF. Le traitement demeure efficace pour soulager les symptômes et les signes de ces deux maladies.

Can. J. Neurol. Sci. 2010; 37: 631-636

Abnormal, involuntary spasms of the periocular and or facial musculature cause a debilitating disorder known as facial dyskinesia. Two common yet distinct forms of facial dyskinesia are essential blepharospasm (EB) and hemifacial spasm (HFS). Essential blepharospasm is a form of dystonia that involves bilateral contraction of the orbicularis oculi muscle and other protractors that causes involuntary eyelid closure. Blepharospasm secondary to ocular surface or adnexal disease must be ruled out. The pathophysiology of the disorder remains elusive although there is evidence suggesting that hyperexcitability of brainstem interneurons secondary to a degenerative change in the basal ganglia plays an important role. ${ }^{1,2}$ Hemifacial spasm is a myoclonus affecting muscles

\footnotetext{
From the Department of Ophthalmology and Vision Sciences, University Health Network and the University of Toronto, Toronto, Ontario, Canada.

Received January 5, 2010. Final Revisions Submitted March 9, 2010. Correspondence to: Dr. Stephen Kraft, The Hospital for Sick Children, 555 University Avenue, Toronto, Ontario, M5G 1X8, Canada.
} 


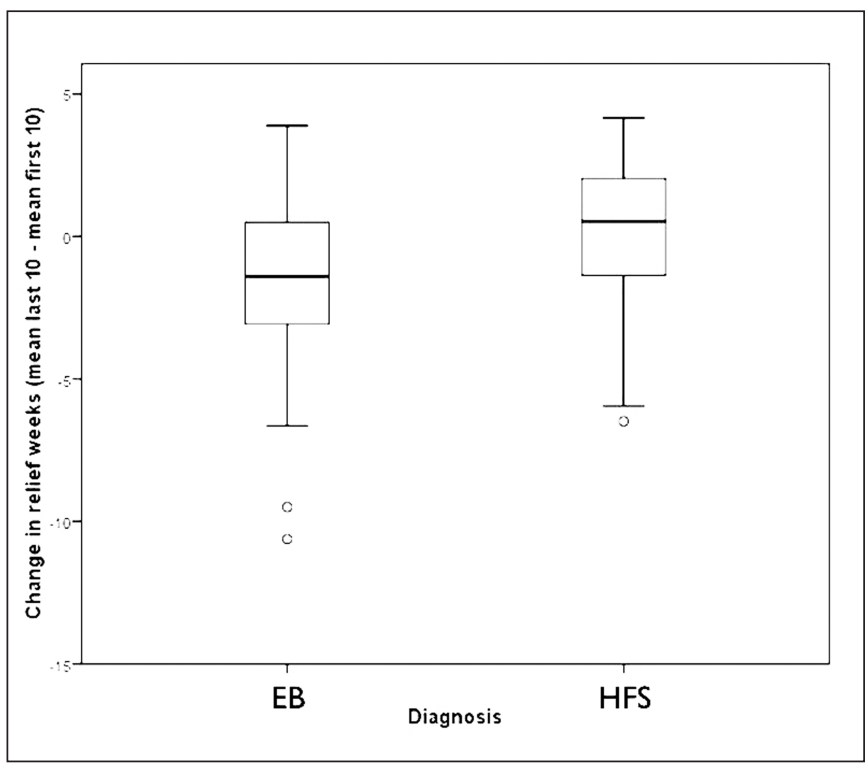

Figure 1: Relief difference (mean duration of relief late session - mean duration of relief early session) for essential blepharospasm (EB) and hemifacial spasm (HFS) patients. Square brackets indicate standard deviation.

innervated by the facial nerve (frontalis, orbicularis oculi, corrugator, orbicularis oris, zygomaticus, platysma) and is almost invariably a unilateral condition. The pathophysiology may involve vascular compression at the exit zone of the seventh cranial nerve root by an aberrant vessel causing axono-axonal ephaptic transmission and hyperexcitability of the facial motonucleus. Neuro-radiological investigation with angiography is recommended. ${ }^{3}$

In the past, EB and HFS were treated with oral medications such as benzodiazepines and surgery. Currently, the preferred first-line management is injection of the periocular and facial musculature with botulinum toxin type A (BtA), which is known to be safe and efficacious. ${ }^{4-6}$ Serial treatments are generally required every few months on an indefinite basis.
There is conflicting evidence regarding the long-term efficacy of BtA in relieving symptoms of EB and HFS. Some studies suggest the duration of relief increases, ${ }^{7,8}$ others suggest it decreases,${ }^{9,10}$ while the majority find a stable duration of benefit over time. ${ }^{6,11-21}$ Knowing how the efficacy of BtA changes over the long-term will allow practitioners to better advise their patients on what to expect regarding dosage and frequency of administration of injections for a life-long disorder.

By looking only at patients who received greater than 30 serial treatments and have been followed on average for more than 15 years, the purpose of this study was to determine whether the period of efficacy of BtA in relieving spasms changes over the long-term. To our knowledge, this report presents data for the longest duration of follow-up and most serial treatment sessions so far available in the literature.

\section{Methods}

The design of this study is a longitudinal retrospective comparative analysis between early and late treatment sessions. A review of medical records of all consecutive patients treated by one practitioner at an academic institutional clinical practice (SPK) between 1985 and 2007 who received 30 or more serial BtA treatments was done. All patients underwent a complete ophthalmologic examination prior to treatment. The Jankovic's rating scale, a clinical tool to quantify the severity and frequency of spasms, was used to grade the disease. It ranges from zero (no signs) to four (severe incapacitating spasms). ${ }^{22}$ The inclusion criteria was a diagnosis of EB or HFS with at least grade two disease before initial treatment. Grade two describes spontaneous eyelid fluttering lasting less than one second duration. Patients with HFS underwent neuroimaging to rule out the possibility of an intracranial lesion. Any patient who had secondary causes for blepharospasm, eyelid apraxia, intracranial pathology or previous eyelid surgery was excluded.

The sites and dosages of BtA injections have been previously described. ${ }^{5}$ Initially, injections were administered at a concentration of five mouse units per $0.1 \mathrm{cc}$. However, both the site and dosage were adjusted according to therapeutic response and with the goal of minimizing adverse effects. The injections were done in both the pretarsal and preseptal orbicularis oculi muscles as well as other involved protractors. Prior to 1991, BtA was supplied under the brand name Oculinum by Smith-

Table 1: Demographic data of patients with essential blepharospasm or hemifacial spasm treated with greater than 30 sessions of serial botulinum toxin A injections

\begin{tabular}{lcc}
\hline & $\begin{array}{c}\text { Blepharospasm } \\
\mathrm{N}=18\end{array}$ & $\begin{array}{c}\text { Hemifacial Spasm } \\
\mathrm{N}=16\end{array}$ \\
\hline Females/Males & $12 / 6$ & $10 / 6$ \\
Mean age at onset of disease (SD), years & $51.2(8.51)$ & $53.8(11.14)$ \\
Mean age at first BtA treatment (SD), years & $54.3(9.04)$ & $57.6(11.54)$ \\
Mean number of BtA treatments (SD) & $53.4(16.25)$ & $50.1(14.07)$ \\
Mean number of total years of treatment (SD) & $16.4(4.35)$ & $15.3(4.15)$ \\
\hline
\end{tabular}

SD-standard deviation 
Kettlewell Institute (San Francisco, CA) and since then has been supplied as Botox by Allergan (Irvine, CA). During every treatment session, the total dose, sites of injection, and presence of adverse effects were noted. The patient was advised to notify the clinic after symptoms returned. Duration of relief was defined as the time from injection to the day of recurrence of symptoms warranting a repeat injection as reported by the patient..$^{5,10}$ When patients called the office they were encouraged to recall precisely the day when symptoms recurred. During the initial treatment sessions, it took weeks to months to establish an effective and stable BtA dose for some patients. In our study we considered the first treatment session for our analysis as that treatment which was able to relieve symptoms for at least a sixweek interval. Almost all patients required at least three or four treatment sessions to determine an appropriate dosage.

Repeated measures analysis of variance models (SAS: Proc mixed) were constructed to examine whether patients showed a change in the mean duration of relief based on session period (early versus late sessions). The mean of the early (first ten) and late (last ten) treatment sessions were used as the outcome variables. A number of predictors were screened for inclusion in the statistical models: 1 . relief difference (mean duration of relief late session - mean duration of relief early session), 2. gender, 3 . current age, 4 . age at onset of disease, 5. age at first treatment, 6 . grade of disease at onset, 7. grade of disease at last visit, 8. total years of treatment, 9. total BtA injections, 10. mean BtA dose of late session, and 11. dose difference (mean dose late session mean dose early session).

There are several reasons to screen variables before combining them into a single statistical model. One reason is to simplify the overall model by including only predictors that appear to show some kind of relationship with the dependent variable in a simply linear model. Another important reason is to satisfy the rule of thumb of ten observations per predictor in order to maintain adequate test power. Because the data sets for the two groups are small, models with greater than one predictor are likely to have low power. Although none of the candidate predictors show a clear relationship to mean duration of relief for either EB or HFS patients, the mean BtA dose in the late session

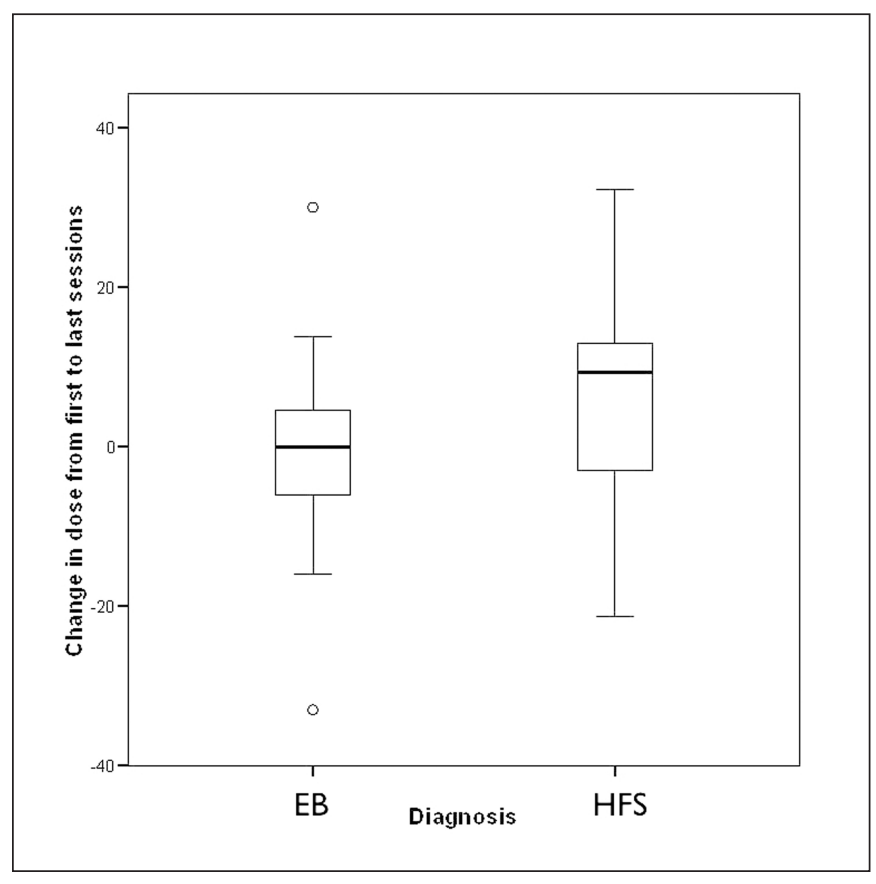

Figure 2: Change in mean BtA dose (units) from early to late sessions for essential blepharospasm (EB) and hemifacial spasm (HFS) patients. Square brackets indicate standard deviation.

was incorporated into statistical models because it showed the best relationship to the outcomes and because it made sense clinically.

Linear regression analysis was done to control for the potential impact of secondary outcome measures as predictors of relief. Secondary outcome measures included total years of treatment, total BtA injections, grade of disease at presentation, and patient demographics.

Table 2: Results of mixed models for the effect of session period (early versus late) on A. Mean duration of relief and $\mathrm{B}$. mean $\mathrm{BtA}$ dose

\begin{tabular}{|c|c|c|c|c|c|}
\hline A. & Mean Duration of & $\begin{array}{l}\text { ation), week } \\
\text { Early }\end{array}$ & Late & $\mathrm{p}^{*}$ & Slope \\
\hline & Blepharospasm & $13.5(3.7)$ & $11.4(3.3)$ & 0.04 & -2.1 \\
\hline & Hemifacial Spasm & $12.4(4.1)$ & $12.4(3.4)$ & 0.91 & -0.09 \\
\hline B. & \multicolumn{5}{|c|}{ Mean BtA Dose (standard deviation), units } \\
\hline & & Early & Late & $\mathrm{p}^{*}$ & Slope \\
\hline & Blepharospasm & $74.7(27.8)$ & $74.1(22.2)$ & 0.85 & -0.06 \\
\hline & Hemifacial Spasm & $32.9(10.1)$ & $38.4(9.1)$ & 0.15 & -0.12 \\
\hline
\end{tabular}

* level of significance $\mathrm{p}<0.05$ 
Table 3: Summary of literature describing the long-term efficacy of $\mathrm{BtA}$ in relieving spasms secondary to EB or HFS

\begin{tabular}{|c|c|c|c|c|c|}
\hline $\begin{array}{l}\text { Lead Author } \\
\text { (No. of cases) }\end{array}$ & $\begin{array}{l}\text { Mean Age } \\
\text { (years) }\end{array}$ & $\%$ Female & $\begin{array}{l}\text { Duration of } \\
\text { Follow-up } \\
\text { (years) }\end{array}$ & $\begin{array}{l}\text { Mean No. BtA } \\
\text { sessions }\end{array}$ & $\begin{array}{l}\text { Mean duration } \\
\text { of relief } \\
\text { (weeks) }\end{array}$ \\
\hline
\end{tabular}

\begin{tabular}{|c|c|c|c|c|c|}
\hline \multicolumn{6}{|c|}{ EB Group } \\
\hline \multicolumn{6}{|c|}{$\overline{\text { No change in duration of relief }}$} \\
\hline $\operatorname{Vogt}^{12}(35)$ & 71 & $66 \%$ & mean 9.9 & not listed & 14.1 \\
\hline Calace $^{17 *}(12)$ & not listed & not listed & mean 12.7 & 26.7 & 19.3 \\
\hline Hsiung $^{16}+(36)$ & 60 & $61 \%$ & $>10$ & $398 \bullet$ & 12 \\
\hline Drummond $^{15}(17)$ & 54 & $71 \%$ & not listed & 16.2 & 11.7 \\
\hline Nussgens $^{18}(60)$ & unknown & $73 \%$ & mean 5.7 & 24.4 & 6.8 \\
\hline \multicolumn{6}{|c|}{ Increasing duration of relief } \\
\hline Cetinkaya (8) $\ell$ & 77 & $75 \%$ & 20.0 & 66.8 & 16.3 \\
\hline \multicolumn{6}{|c|}{ Decreasing duration of relief } \\
\hline Ainsworth $^{10}(20)$ & 66 & $60 \%$ & range $5-9$ & 19.3 & 16.6 \\
\hline Gill (18) & 54 & $67 \%$ & mean 16.4 & 53.4 & 11.4 \\
\hline \multicolumn{6}{|c|}{ HFS Group } \\
\hline \multicolumn{6}{|c|}{ No change in duration of relief } \\
\hline $\operatorname{Vogt}^{12}(43)$ & 66 & $44 \%$ & mean 8.9 & not listed & 16.3 \\
\hline Hsiung ${ }^{16}+(70)$ & 57 & $57 \%$ & $>10$ & $630 \bullet$ & 12 \\
\hline Drummond $^{15}(11)$ & 53 & $55 \%$ & not listed & 10.8 & 15.1 \\
\hline Jitpimolmard ${ }^{19} *(2$ & not listed & not listed & mean 2.3 & $>12$ & range $10.6-17.2$ \\
\hline Flanders ${ }^{20} *(51)$ & not listed & not listed & $<8$ & not listed & 18.9 \\
\hline Defazio $^{21}(65)$ & 56 & $70 \%$ & $>10$ & not listed & 13.5 \\
\hline Gill (16) & 58 & $62 \%$ & mean 15.3 & 48.7 & 12.4 \\
\hline \multicolumn{6}{|c|}{ Increasing durationof relief } \\
\hline Cetinkaya (3) $R$ & 85 & $100 \%$ & 20.5 & 83.3 & 16.3 \\
\hline \multicolumn{6}{|c|}{ Decreasing duration of relief } \\
\hline Ainsworth $^{10}(12)$ & 62 & $67 \%$ & range $5-9$ & 16.6 & 18.5 \\
\hline
\end{tabular}

*only the data pertaining to the subgroup of patients that were followed long-term in these studies is included; + this study does not describe how the duration of relief changes over time; $\bullet$ these values represent total treatment cycles for the entire patient group; \& Duration of relief not separated for EB and HFS patients in this study (Cetinkaya A, Kulwin DR. Twenty years of botulinum toxin on the face. Poster presented at: AAO Annual Meeting, November 8, 2008; Atlanta)

\section{RESULTS}

We had 18 patients with EB and 16 patients with HFS who met the inclusion criteria. Data was analyzed independently for the two groups. Tables 1 and 2 present the demographic and treatment data. Most patients were in their sixth and seventh decades of life when treatment began. Disease grade at both onset and at last visit was most commonly grade 3 (out of 4 on the Jankovic scale). ${ }^{22}$ Only two patients reported adverse effects after the injection including dry eyes (1) and temporary ptosis (1) over the follow-up period.

\section{Change in Duration of Relief}

Patients with EB experienced an average of 13.5 weeks of relief in the early session period (first ten treatments) and 11.4 weeks in the late session period (last ten treatments) while patients with HFS experienced an average of 12.4 weeks of relief regardless of session period (Table 2A). Figure 1 shows overall changes in duration of relief for both groups and suggests that relief declined more for the EB patients - an average of 2.1 fewer weeks of relief in the late session period. In the EB group, the average of 2.1 fewer weeks of relief in the late session period compared with the early session period was barely statistically significant $(\mathrm{P}=0.04)$. In the HFS group, there was no difference in average duration of relief between session periods $(\mathrm{P}=0.91)$.

The statistical model analyzed the effect of duration of relief versus mean BtA dose in the late session. The duration of relief was found to have a small negative correlation with mean BtA dose in the late session in the EB group $(\mathrm{P}=0.03)$ but had no correlation in the HFS group $(\mathrm{P}=0.12)$.

\section{Change in BtA Dose}

Table $2 \mathrm{~B}$ shows the mean BtA dosages for the early and late sessions for both groups of patients. A repeated measures 
analysis of variance (ANOVA) showed that BtA dose did not change significantly from early to late sessions for patients in either group $(\mathrm{EB}: \mathrm{P}=0.85$, HFS: $\mathrm{P}=0.15)$. No other predictors were used in this model (Figure 2).

Two patients in the $\mathrm{EB}$ group required a change in BtA concentration over their course of treatment. One patient had a total of 45 treatment sessions and required an increase in concentration from $60 \mathrm{U}$ to $90 \mathrm{U}$ between his 29 th and 35 th sessions. The second patient had a total of 49 treatment sessions and required a decrease in concentration from $120 \mathrm{U}$ to $60 \mathrm{U}$ between her 31st and 39th sessions. A total of seven patients in the HFS group required an increase in concentration by 10 to $20 \mathrm{U}$ between their 30 th and 40th treatment sessions. The additional medication was necessary mostly for injections to the midface and perioral area in the HFS group.

Linear regression analyses done to control for the secondary outcome measures as predictors of relief were not statistically significant.

\section{DISCUSSION}

All patients with EB presented with bilateral symptoms and those with HFS presented with unilateral symptoms. Bilateral HFS is a rare phenomenon that would present a diagnostic challenge. ${ }^{23}$ The first-line management for the involuntary, spasmodic muscle contractions causing EB and HFS is regular intramuscular injections with BtA. This neurotoxin binds with high affinity and specificity to presynaptic cholinergic nerve terminals and inhibits the release of acetylcholine, thereby preventing muscular contraction. The neuromuscular endplate becomes disorganized temporarily. However, compensatory axonal sprouting begins by four days after treatment and permits partial recovery of function by about four weeks. ${ }^{24}$ After eight weeks, the original endplates begin to release acetylcholine and by 12 weeks they are back to normal function. ${ }^{25}$ This reestablishment of muscle function necessitates repeat BtA injections. Although most studies agree that the average duration of relief is 12 weeks, there is some evidence that this duration may change over time after multiple and repeated treatments. ${ }^{7}$

Our study found that after 30 or greater (EB mean 53.4, HFS mean 48.7) serial BtA treatment sessions, the duration of relief remains clinically effective for patients with either EB or HFS. BtA provided an average of 11.4 weeks of relief for EB patients and 12.4 weeks of relief for HFS patients during their last ten treatment sessions. The data demonstrate a trend for a small decrease in duration of relief over time in the EB group when comparing the late to the early sessions. The same is not true for the HFS group, which demonstrated a stable duration of relief over time.

Although there was a trend towards a greater BtA dose in HFS patients over time, there was no statistically significant difference between the dose in either group when comparing early and late sessions (EB: $\mathrm{P}=0.85$, HFS: $\mathrm{P}=0.15)$. Hsiung et al also found a trend towards increased BtA dosage over time for HFS patients although it was not statistically significant. ${ }^{16}$ This finding may be explained by a low level of antibody production that neutralizes the toxin. ${ }^{26}$

Our study also found that the duration of relief has a small negative correlation with total BtA dose late session in the EB group $(\mathrm{P}=0.03)$ but no correlation in the HFS group $(\mathrm{P}=0.12)$.
This correlation may be explained by the fact that as the duration of relief decreased in some patients in the EB group, the dosage of the medication was correspondingly increased in effort to maintain therapeutic benefit.

Table 3 summarizes the results of studies that have looked at the long-term efficacy of BtA in relieving symptoms of EB and or HFS. Our results support conclusions from the prior study from our center for EB, which had much shorter follow-up but showed a slight decline in relief interval with time. ${ }^{10}$ This contrasts with the data of other authors, also with shorter followup, who found no change in relief intervals for EB cases. ${ }^{11,12,15-}$ ${ }^{18}$ On the other hand, our current study did not support the trend in our earlier study of declining duration of relief for HFS patients ${ }^{10}$ but rather showed no overall decline when analyzing results beyond 30 sessions. This confirms findings of other studies. ${ }^{12,15,16,19-21}$ Finally, Cetinkaya and Kulwin in a recent study looking at patients with focal dystonias combining the results for both EB and HFS patients, showed a trend of increased duration of relief and an increased dose requirement over time, with the yearly-injected dose remaining stable (Cetinkaya A, Kulwin DR. Twenty years of botulinum toxin on the face. Poster presented at: American Academy of Ophthalmology Annual Meeting, November 8, 2008; Atlanta). Their main conclusion that BtA remains effective over the longterm supports our own.

There are limitations to our study. The number of subjects was small in each group, although statistical tests with adequate power to include one predictor was possible. Because we only looked at patients who received at least 30 serial treatments, rather than an entire patient cohort over a defined period of time, there is potentially spectrum bias. Thus, our results may be applicable only to those patients who require and receive the greatest number of treatment sessions rather than to the full spectrum of disease, in which some patients may respond extremely well and have very long durations of relief and accordingly, less treatment sessions, while others may not respond to BtA at all. Potential confounders include inter- and intra-patient variability in perception of relief from symptoms after BtA injections, which can be related to stress, fatigue, and other factors. ${ }^{10}$ The fact that BtA onset may be delayed is also a potential confounder, but we tried to minimize this bias by defining the early sessions as the first ten after a stable dose had been reached. Furthermore, we did not distinguish whether the injection sites were pretarsal, preseptal, or both as all patients received injections at both these sites. Several studies support a pretarsal injection site because it seems to produce a higher response rate and longer duration of benefit. ${ }^{27,28}$ Finally, we only looked at those patients who had sustained benefit after several years (greater than 30 treatments, followed on average more than 15 years), and did not look at the actual number of patients who developed resistance to treatment over time. However, it is accepted that EB and HFS are not commonly resistant to BtA treatment (0-3\%) and that more than $80-90 \%$ continue to benefit over time. ${ }^{16}$ It has been shown that no relation exists between patient age, gender, grade or duration of disease, and duration of relief with BtA. ${ }^{10}$ 


\section{Conclusion}

After long-term serial treatments with BtA, the duration of relief from symptoms remains unchanged in patients with HFS, while there may be a trend towards a slight decrease in duration of relief in patients with EB. Overall, patients with either condition may be reassured that the dosage and duration of relief remain clinically effective after 30 or more serial BtA treatment sessions.

\section{ACKNOWLEDGEMENTS}

Supported by a grant from the Benign Essential Blepharospasm Canadian Research Foundation Inc. Dr. Laurel Duquette Ph.D.,Department of Statistics, University of Toronto, provided statistical consultation and support.

\section{REFERENCES}

1. Jankovic J, Ford J. Blepharospasm and orofacial-cervical dystonia: clinical and pharmacological findings in 100 patients. Ann Neurol. 1983;13:402-11.

2. Berardelli A, Rothwell JC, Day BL, Marsden CD. Pathophysiology of blepharospasm and oromandibular dystonia. Brain. 1985; 108: 593-608.

3. Adler CH, Zimmerman RA, Savino PJ, Bernardi B, Bosley TM, Sergott RC. Hemifacial spasm: evaluation by magnetic resonance imaging and magnetic resonance tomographic angiography. Ann Neurol. 1992;32:502-6.

4. Elston JS. The management of blepharospasm and hemifacial spasm. J Neurol. 1992;239:5-8.

5. Taylor JDN, Kraft SP, Kazdan MS, Flanders M, Cadera W, Orton RB. Treatment of blepharospasm and hemifacial spasm with botulinum A toxin: a Canadian multicentre study. Can J Ophthalmol. 1991;26:133-8.

6. Carruthers J, Stubbs HA. Botulinum toxin for benign essential blepharospasm, hemifacial spasm and age-related lower eyelid entropion. Can J Neurol Sci. 1987;14:42-5.

7. Carruthers J. Ophthalmologic use of botulinum A exotoxin. Can J Ophthalmol. 1985;20:135-41.

8. Lingua RW. Sequelae of botulinum toxin injection. Am J Ophthalmol. 1985;100:305-7.

9. Kraft SP, Lang AE. Botulinum toxin injections in the treatment of blepharospasm, hemifacial spasm, and eyelid fasciculations. Can J Neurol Sci. 1988;15:276-80.

10. Ainsworth JR, Kraft SP. Long-term changes in duration of relief with botulinum toxin treatment of essential blepharospasm and hemifacial spasm. Ophthalmology. 1995;102:2036-40.

11. Dutton JJ, Buckley EG. Long-term results and complications of botulinum A toxin in treatment of blepharospasm. Ophthalmology. 1988;95(12):1529-34.

12. Vogt T, Lussi F, Paul A, Urban P. Long-term therapy of focal dystonia and facial hemispasm with botulinum toxin A. Nervenarzt. 2008;79:912-17.
13. Mauriello JA, Coniaris H, Haupt EJ. Use of botulinum toxin in the treatment of one hundred patients with facial dyskinesias. Ophthalmology. 1987;94:976-9.

14. Shorr N, Seiff SR, Kopelman J. The use of botulinum toxin in blepharospasm. Am J Ophthalmol. 1985;99:542-6.

15. Drummond GT, Hinz BJ. Botulinum toxin for blepharospasm and hemifacial spasm: stability of duration of effect and dosage over time. Can J Ophthalmol. 2001;36(7):398-403.

16. Hsiung GYR, Das SK, Ranawaya R, Lafontaine AL, Suchowersky O. Long-term efficiacy of botulinum toxin A in treatment of various movement disorders over a 10 -year period. Movement Disord. 2002;17(6):1288-93.

17. Calace P, Cortese G, Piscopo R, Della Volpe G, Gagliardi V, Magli $\mathrm{A}$, et al. Treatment of blepharospasm with botulinum neurotoxin type A: long-term results. Eur J Ophthalmol. 2003;13(4):331-6.

18. Nussgens Z, Roggenkamper P. Long-term treatment of blepharospasm with botulinum toxin type A. Ger J Ophthalmol. 1995;4:363-7.

19. Jitpimolmard S, Tiamkao S, Laopaiboon M. Long term results of botulinum toxin type A (Dysport) in the treatment of hemifacial spasm: a report of 175 cases. J Neurol Neurosurg Psychiatry. 1998;64:751-7.

20. Flanders $M$, Chin D, Boghen D. Botulinum toxin: preferred treatment for hemifacial spasm. Eur Neurol. 1993;33(4):316-19.

21. Defazio G, Abbruzzese G, Girlanda P, Vacca L, Curra A, De Salvia $\mathrm{R}$, et al. Botulinum toxin A treatment for primary hemifacial spasm. A 10-year multicenter study. Arch Neurol. 2002;59: 418-20.

22. Jankovic J, Schwartz K. Botulinum toxin injections for cervical dystonia. Neurology. 1990;40:277-80.

23. Tan EK, Jankovic J. Bilateral hemifacial spasm: a report of five cases and a literature review. Movement Disord. 1999;14(2): 345-9.

24. Bonner PH, Friedli AF, Baker RS. Botulinum A toxin stimulates neurite branching in nerve-muscle cocultures. Dev Brain Res. 1994;79:39-46.

25. Kessler KR, Benecke R. Botulinum toxin: from poison to remedy. Neurotoxicology. 1997;18(3):761-70.

26. Borodic G, Johnson E, Goodenough M, Schantz E. Botulinum toxin therapy, immunological resistance, and problems with available materials. Neurology. 1996;46:26-30.

27. Cakmur R, Ozturk V, Uzunel F, Donmez B, Idiman F. Comparison of preseptal and pretarsal injections of botulinum toxin in the treatment of blepharospasm and hemifacial spasm. J Neurol. 2002;249:64-8.

28. Jankovic J. Pretarsal injection of botulinum toxin for blepharospasm and apraxia of eyelid opening. J Neurol Neurosurg Psychiatry. 1996;60(6):704.

Poster Reference: Cetinkaya A, Kulwin DR. Twenty years of botulinum toxin on the face. Presented as a poster at the annual meeting of American Academy of Ophthalmology, Atlanta, GA, Nov 8-11, 2008. (e-abstract: http://www.scientificposters.com/ aao/aaoView.cfm? pid=468\&yr=2008) 